\title{
Impact of the quality of food sources on the wing beating of honey bee dancers
}

\author{
Sylwia ŁoPUCH, Adam ToFILSKI \\ Department of Zoology and Animal Welfare, Faculty of Animal Science, University of Agriculture in Krakow, Al. 29 \\ Listopada 56, 31-425, Krakow, Poland
}

Received 5 August 2019 - Revised 11 January 2020 - Accepted 6 February 2020

\begin{abstract}
The waggle dances of honey bees provide information about the location of food sources and their quality. This study aimed to investigate how the quality of food sources affects different components of the dance. For the first time, we analysed in detail both the waggle phase and the return phase of the dance using a high-speed camera. The frequency of wing beats in the waggle phase and the frequency of wing-beating pulses in the return phase were significantly higher in foragers collecting more concentrated honey compared with foragers collecting less-concentrated honey, whereas the duration of the return phase was significantly shorter. Discriminant function analysis allowed correct classification of $88.1 \%$ of dances as referring to 60 or $40 \%$ honey concentration. In conclusion, information about the quality of food sources can be contained both in the waggle phase and in the return phase; however, the return phase appears to transfer more information about the quality of food sources.
\end{abstract}

\section{honey bee / wing beats / high-speed camera / food-source quality}

\section{INTRODUCTION}

The communication of honey bee (Apis mellifera) workers by means of waggle dances has been studied for many decades. Workers dance on the comb in the nest to inform their nestmates about the location of a useful resource, including a source of food or a new nest site (von Frisch 1967). Honey bee dance consists of many circuits which, in turn, consist of a waggle phase and a return phase (Figure 1). Because dances are

Electronic supplementary material The online version of this article (https://doi.org/10.1007/s13592-020-00748-3) contains supplementary material, which is available to authorized users.

Corresponding author: S. Łopuch,

Sylwia.Lopuch@urk.edu.pl

Handling Editor: Cédric Alaux performed in the darkness of nest, it is unlikely that visual cues are used to transfer information contained in the dance. Most likely the dance information is encoded in vibrations, sounds, olfactory, or tactile cues (Michelsen et al. 1986a, 1987; Tautz 1996; Rohrseitz and Tautz 1999; Thom et al. 2007). It is well documented that honey bee dances contain information about distance (included in the duration of the waggle phase and the number of abdomen waggles in the waggle phase; von Frisch and Jander 1957) and direction (included in the angle of the waggle phase relative to vertical; von Frisch 1967).

It was also reported that honey bee dances provide information about the quality of resources (von Frisch 1967). More profitable food sources elicit more vigorous and longer-lasting dances (Boch 1956; Esch 1961; von Frisch 1967; Seeley et al. 1991, 2000), which may also attract more dance followers. Food-source profitability 


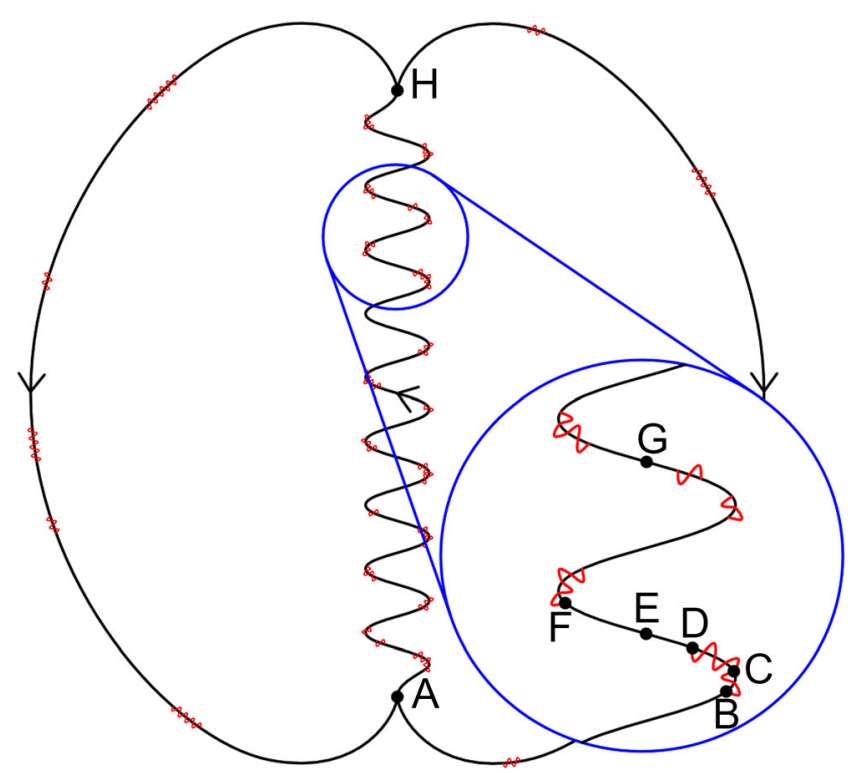

Figure 1. Schematic of honey bee waggle dance. The position of abdomen is indicated by a black line. The up and down wing beats are indicated by a red line to the left and to the right of the black line, respectively. Part of the waggle phase was enlarged to better illustrate wing beats. Direction of the dance is indicated with arrows. Waggle phase - a part of the dance indicated by the black line between points A and H. Duration of waggle phase - time elapsed when a dancer moved from point A to $\mathrm{H}$. Abdomen waggle - a part of the waggle phase indicated by the black line between points E and G. Return phase - a part of the dance indicated by either of the two black lines between points $\mathrm{H}$ and A. Duration of return phase - time elapsed when a dancer moved from points $\mathrm{H}$ to A. Pulse of wing-beating - a part of the waggle phase or the return phase indicated by the red line between points B and D. Duration of one wing-beating pulse - duration of a series of wing beats performed by a dancer between points B and D. Wing beat - a part of the waggle phase or the return phase indicated by the red line between points B and C. Combined duration of wing beating - the duration of all wing-beating pulses performed during the waggle phase or the return phase. Duration of interval between wing-beating pulses - time elapsed between the end of one pulse and the beginning of the next pulse of wing beating (when a dancer travelled from points $\mathrm{D}$ to F). Frequency of abdomen waggles, wing-beating pulses or wing beats - number of waggles, pulses, or wing beats performed per second.

depends on energetic gains and costs of foraging associated with many different factors including sugar concentration, abundance, and distance to the food source (Núñez 1982; Waddington 1982; Núñez and Giurfa 1996). The number of dance circuits and the duration of waggle dances increase with rising profitability of food sources (Seeley 1986, 1994; Seeley et al. 1991, 2000; Seeley and Towne 1992; Farina 1996; De Marco and Farina 2001). Similarly, the number of reversals in a round dance, the duration of round dances and the rate of reversals have shown a positive correlation with rising sugar concentration (Waddington 1982; Waddington and Kirchner 1992; Waddington et al. 1998). Food sources of better quality have also been shown to increase the probability of dancing (Seeley 1986; Seeley et al. 1991; Waddington and Kirchner 1992; Farina 1996; Hrncir et al. 2011).

Dance followers usually do not follow the whole dance, which can consist of 1 to 100 circuits (Seeley et al. 2000). They follow from six to eight consecutive dance circuits before leaving the nest (Esch and Bastian 1970; Judd 1995). For a single bee, therefore, more important may be the information contained in single dance circuits, and not the whole sequence of dances. This assumption appears to be supported by the findings that more profitable food sources are associated with shorter dance circuit (Hrncir et al. 2011) and shorter return phase (Seeley et al. 2000; Hrncir et al. 2011), higher probability of producing dance 
sounds or thoracic vibrations during the waggle phase (Waddington and Kirchner 1992; Hrncir et al. 2011), shorter interval duration between the pulses of thoracic vibrations (Hrncir et al. 2011) and longer pulse duration of dance sounds or thoracic vibrations (Waddington and Kirchner 1992; Hrncir et al. 2011). Moreover, rising profitability of food sources have increased the frequency of abdomen waggles (i.e. the number of waggles per second; Seeley et al. 1991, 2000), the pulse rate (i.e. the number of pulses per second) of dance sounds (Esch 1963; Wenner et al. 1967; Waddington and Kirchner 1992) and the frequency of dance sounds (i.e. the number of sounds per second; Waddington and Kirchner 1992), but not in all studies (Wenner et al. 1967; Hrncir et al. 2011). Under circumstances where the concentration of sugar was constant but distances between the nest and feeders were different, the frequency of wing vibrations in the waggle phase decreased as the distance increased (Spangler 1991), but not in all studies (Esch 1961; Eskov 1969 cited by Spangler 1991). As can be seen, the quality of food sources and the distance to food sources may influence several features of honey bee dance. Nevertheless, honey bee communication of the food-source profitability by means of a dance still remains unclear.

In our previous paper (Łopuch and Tofilski 2017a), it was hypothesised that the frequency of wing beats, wing-beating pulses and abdomen waggles, which were strongly positively correlated with each other and differed markedly among dances, could transfer information about the foodsource profitability. Moreover, this group of dance components were strongly negatively correlated with the other group of dance components transferring the distance information which were also strongly positively correlated with each other. As was mentioned before, food-source profitability depends on the energetic gains and costs of foraging (Núñez 1982; Waddington 1982; Núñez and Giurfa 1996); therefore, negative correlations between the two described groups of dance components might be explained by food-source profitability.

The aim of this study was to determine how the quality of food sources influences the frequency of wing beats, wing-beating pulses and abdomen waggles in honey bee dance. For this purpose, honey bee foragers were trained to fly to an artificial feeder filled with honey solution at two different concentrations (40 or $60 \%$ ). Their dances, performed after their return to the observational hives, were recorded with the use of a high-speed camera. For the first time, we analysed in detail not only the waggle phase but also the return phase of a dance which may contain more information about the food-source profitability because it does not transfer the distance information as the waggle phase does. It was predicted that a food source of higher quality will be associated with higher frequency of wing beats, wingbeating pulses and abdomen waggles in single circuits of honey bee dance (both in the waggle phase and the return phase).

\section{MATERIALS AND METHODS}

\subsection{Samples}

The experiment was conducted on two colonies of honey bees (A. mellifera carnica) housed in the observation hives at the laboratory of the University of Agriculture in Krakow. The observation hives consisted of six frames. Two of them were located behind glass walls which allowed the recording of dancing bees. Each colony consisted of about 12,000 bees. Neither colony showed any symptoms of diseases other than a Varroa mite infestation, which was mild because it was controlled by an acaricide. All applicable international, national and institutional guidelines for the care and use of animals were followed.

\subsection{Data collection}

Workers were trained to collect 40 or $60 \%$ solution made of buckwheat honey dissolved in water (40 or $60 \mathrm{~g}$ solute/100 g solution). A feeder was placed at a distance of about $40 \mathrm{~m}$ from the observation hives. The feeder was filled with 40 or $60 \%$ honey solution on a given day. Trained workers were marked by means of paints in different colours. The non-marked workers were captured and released at the end of the day. The experiment was conducted from 22 August to 18 September 2018. 
Dances were recorded with the use of a highspeed camera (Phantom MIRO eX4, Vision Research, Inc. USA). An LED lamp (LEDIM616, $50 \mathrm{~W}$, Ledim, Poland) was used as the light source because it does not emit too much heat and does not disturb the behaviour of honey bees by flickering. Videos were recorded with a sample rate of $2900 \mathrm{fps}$ at a resolution of $512 \times 384$ pixels. Each frame lasted $344.75 \mu \mathrm{s}$. At this settings, our equipment allowed to record continuously for about $5 \mathrm{~s}$ which is long enough to fit at least one full dance circuit containing both waggle phase and return phase. In order to record full dance circuit, we used relatively short foraging distance associated with shorter waggle phases of dances. The video recordings were made and analysed using PCC software, version 2.6 (Vision Research, 2015).

During dance, workers perform a specific behaviour of wing beating (Figure 1; Online resource 1a-d; see also Łopuch and Tofilski 2017a, b). A wing beat was defined as a complete cycle of wing movement up and down. The dancers usually performed a series of wing beats which were called wing-beating pulses. These pulses were separated by the intervals when the wings were immobile. An abdomen waggle was defined as a complete cycle of abdomen movement from side to side and back. Analysis of the video data included the dance components defined in Figure 1. The analysis included 42 dances $(60 \%$ honey solution, 8 dances in colony 1 and 16 dances in colony 2; 40\% honey solution, 8 dances in colony 1 and 10 dances in colony 2). Each dance consisted of at least one waggle phase and return phase. In 35 recordings, it was possible to analyse more than one waggle phase or one return phase.

\subsection{Data analysis}

All data were checked for deviation from the normal distribution. In the case of a lack of normal distribution, the analysed data were ln-transformed. This normalization was required in the case of the frequency of wing-beating pulses in the waggle phase and the interval duration between wing-beating pulses in the waggle phase. The strength of associations between analysed data was assessed by Pearson correlation. Bonferroni correction was performed to reduce the risk of falsely reporting a statistical significance when multiple comparisons were made. After Bonferroni correction, correlations were assumed to be significant when $p<0.003$. Mantel test was conducted to compare correlation matrices. Principal component analysis was used to convert correlated variables into linearly uncorrelated variables and to reduce their number to those which would explain the largest proportion of the total variance. MANOVA was performed to assess the differences between the analysed groups. Discriminant analysis was conducted to analyse the contribution of different components of dances performed by foragers collecting 60 or $40 \%$ honey solution to the overall discrimination. All tests used were two tailed. The statistical analyses were conducted using Statistica, version 12.0 (Statsoft Inc 2013). The recorded video data were not blinded because the observer was not able to assess the parameters of dances before their precise analysis.

\section{RESULTS}

Correlation matrices of components of dances performed by honey bee foragers collecting 40 or $60 \%$ honey solution were significantly correlated with each other (Mantel test: $r=0.059, p<$ 0.001). Therefore, we assumed that they do not differ from each other and the results were combined (Table I). The correlation matrix of 18 dance components showed that there were 31 significant correlations (20.6\% of all correlations) after taking into account Bonferroni correction. Most of these significant correlations were positive; only five significant correlations were negative. Dance components corresponding to each other in the waggle phase and in the return phase were significantly correlated with each other. The only exceptions were the interval duration between wingbeating pulses and the frequency of wing-beating pulses.

Because various components of dances were strongly correlated with each other, principal component analysis was used to reduce the number of variables from 18 to five components that explained $81.3 \%$ of variance (Online resource 2). Further analysis of these five principal components using MANOVA demonstrated that there were significant differences between dances of 
Table I. Correlation matrix between components of dances performed by honey bee foragers from two colonies fed with 40 or $60 \%$ honey solution (Bonferroni correction $p=0.003$ )

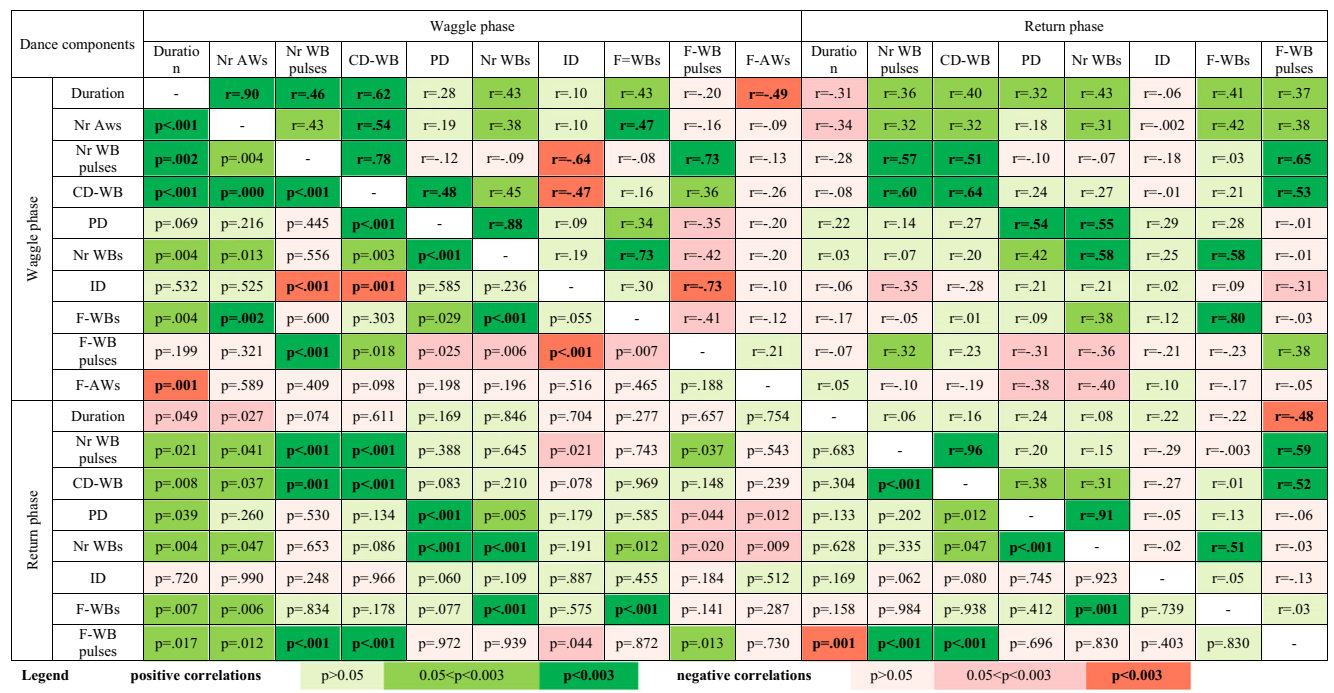

Abbreviations: $N r A W s$ - number of abdomen waggles; $N r W B$ pulses - number of wing-beating pulses; $C D-W B$ - combined duration of wing beating; $P D$ - pulse duration (i.e. duration of one pulse of wing beating); $N r W B s$ - number of wing beats in one pulse of wing beating; $I D$ - interval duration between wing-beating pulses; $F$-Wbs - frequency of wing beats; $F$-WB pulses frequency of wing-beating pulses; $F$-Aws - frequency of abdomen waggles

foragers collecting 40 or $60 \%$ honey solution $\left(F_{5}\right.$, $34=4.49, p=0.030)$ and between the colonies $\left(F_{5,34}=6.30, p<0.001\right)$. The interaction between honey concentration and colony was insignificant $\left(F_{5,34}=0.73, p=0.603\right)$.

The frequency of wing beats in the waggle phase and the frequency of wing-beating pulses in the return phase were significantly higher in a group of foragers collecting $60 \%$ honey solution compared with foragers collecting $40 \%$ honey solution, whereas the duration of the return phase was significantly shorter (Table II; Figure 2).

Discriminant function analysis allowed correct classification of $88.1 \%$ of dances as referring to 60 or $40 \%$ concentration of honey. Eight out of eighteen variables were selected for the discrimination model using a stepwise procedure. The frequency of wing-beating pulses and the number of wing beats in one pulse of wing beating in the return phase, as well as the frequency of wing beats and the combined duration of wing beating in the waggle phase contributed the most to the overall discrimination (Table III).

\section{DISCUSSION}

The results presented here indicate that the waggle dances of honey bee foragers depended markedly on concentration of honey solution they collected. This confirms earlier findings that the waggle dance can transfer information about the food-source quality (Esch 1963; Wenner et al. 1967; Waddington and Kirchner 1992; Seeley et al. 2000; Hrncir et al. 2011). In the present study, the most important dance component seems to be the frequency of wing-beating pulses in the return phase, because foragers collecting more concentrated honey produced the wing-beating pulses two times more often than those collecting less-concentrated honey (Table II; Figure 2c). The dances of foragers collecting honey at different concentrations also significantly varied in the frequency of wing beats in the waggle phase and the duration of the return phase. It must be stressed that there were strong correlations between various dance components. In this situation, it is difficult to 
suggest that a single dance component provides the most information about food-source quality.

In earlier studies, it was reported that higher food profitability was associated with a higher frequency of vibrations recorded as dance sounds (Waddington and Kirchner 1992) or thoracic vibrations (Hrncir et al. 2011) and a higher frequency of vibration pulses (Esch 1963; Wenner et al. 1967; Waddington and Kirchner 1992) in the waggle phase. Some findings in the present study are consistent with the results of these studies. Foragers fed with more concentrated honey moved their wings with higher frequency in the waggle phase, which may correspond to the increase of the frequency of dance sounds or thoracic vibrations produced by bees in response to rising sugar concentration (Waddington and Kirchner 1992) or solution flow rate (Hrncir et al. 2011). Similarly, the higher frequency of wing vibrations in the waggle phase correlated with decreasing distance from the nest to the food sources (Spangler 1991) may be explained in terms of increasing food-source profitability. However, in other studies the frequency of dance sounds was not significantly affected by sugar concentration (Esch 1961; Wenner et al. 1967; Eskov 1969 cited by Spangler 1991). In the waggle phase, the pulse rate of dance sounds also increased with higher sugar concentration (Esch 1963; Wenner et al. 1967; Waddington and Kirchner 1992), but the pulse rate of thoracic vibrations did not increase (Hrncir et al. 2011). We did not find a significant difference between the frequency of wingbeating pulses in the waggle phase produced by foragers collecting honey of different concentrations, either, but we found that bees fed with more concentrated honey produced a significantly higher frequency of wing-beating pulses in the return phase. Moreover, the duration of the return phase was significantly shorter in dances performed by foragers fed with more concentrated honey, similar to previous findings showing that the return phase duration decreased along with rising sugar concentration (Seeley et al. 2000; Hrncir et al. 2011). This indicates that the return phase, which has received a little attention to date, contains important information about the food-source profitability. Because foragers performed only a few wing-beating pulses in the return phase, which constituted of 5 and $9 \%$ of its duration in a groups of foragers collecting 40 and $60 \%$ solution, respectively, it is unlikely that higher frequency of wingbeating pulses was a result of shorter duration of the return phase in a group of foragers collecting more concentrated honey solution.

In our previous paper (Eopuch and Tofilski 2017a), we reported about two groups of dance components in the waggle phase which were strongly negatively correlated with each other, but these were strongly positively correlated with each other within groups. One of these groups included the duration of the waggle phase, the number of abdomen waggles and wing-beating pulses, as well as the combined duration of wing beating, whereas the second group included the frequency of wing beats, wing-beating pulses and abdomen waggles, as well as the number of wing beats in one pulse of wing beating. The first group most probably provides information about the foraging distance, because the combined duration of wing beating and the number of wingbeating pulses were closely related to the duration of the waggle phase and the number of abdomen waggles (Łopuch and Tofilski 2017a; the present study), which were proved to transfer a distance information (von Frisch and Jander 1957). We have also hypothesised that the second group provides information about the food-source profitability. The results presented here confirmed that the frequency of wing beats in the waggle phase is strongly linked with honey concentration but not other dance components from this group. Therefore, the present data do not support the assumption that the dance components from the second group provide information about the quality of food source.

Food-source profitability depends on the energetic gains and costs of foraging associated with many factors such as sugar concentration, abundance or distance to the food source 
Table II. The mean $( \pm \mathrm{SD})$ values and the results of univariate tests of ANOVA comparing dances of honey bee foragers from two colonies fed with 40 or $60 \%$ honey solution

\begin{tabular}{|c|c|c|c|c|c|}
\hline \multirow[t]{2}{*}{ Variables } & \multicolumn{2}{|c|}{ Honey concentration } & \multicolumn{3}{|c|}{ Source of variation ( $p$-values) } \\
\hline & $\begin{array}{c}40 \%(N=18) \\
\text { Mean } \pm \text { SD }\end{array}$ & $\begin{array}{l}60 \%(N=24) \\
\text { Mean } \pm \mathrm{SD}\end{array}$ & Concentration & Colony & Interaction \\
\hline \multicolumn{6}{|l|}{ Waggle phase } \\
\hline Duration (ms) & $306.0 \pm 65.69$ & $336.5 \pm 71.14$ & 0.234 & 0.013 & 0.856 \\
\hline Number of abdomen waggles $(n)$ & $4.2 \pm 0.80$ & $4.5 \pm 0.78$ & 0.269 & 0.004 & 0.897 \\
\hline Number of wing-beating pulses $(n)$ & $8.5 \pm 2.21$ & $8.8 \pm 3.19$ & 0.980 & 0.778 & 0.186 \\
\hline $\begin{array}{l}\text { Combined duration of wing beating } \\
(\mathrm{ms})\end{array}$ & $153.0 \pm 47.05$ & $157.9 \pm 64.29$ & 0.900 & 0.100 & 0.350 \\
\hline $\begin{array}{l}\text { Duration of one wing-beating pulse } \\
(\mathrm{ms})\end{array}$ & $18.0 \pm 4.93$ & $18.5 \pm 3.12$ & 0.685 & 0.015 & 0.294 \\
\hline $\begin{array}{l}\text { Number of wing beats in one pulse } \\
\text { of wing beating }(n)\end{array}$ & $4.2 \pm 1.44$ & $4.5 \pm 1.14$ & 0.463 & $<0.001$ & 0.237 \\
\hline $\begin{array}{l}\text { Interval duration between } \\
\text { wing-beating pulses (ms) }\end{array}$ & $16.0 \pm 6.96$ & $19.8 \pm 9.58$ & 0.178 & 0.064 & 0.161 \\
\hline Frequency of wing beats $(\mathrm{Hz})$ & $220.4 \pm 36.79$ & $245.9 \pm 33.65$ & 0.020 & $<0.001$ & 0.301 \\
\hline $\begin{array}{l}\text { Frequency of wing-beating pulses } \\
\text { (Hz) }\end{array}$ & $28.5 \pm 8.17$ & $25.9 \pm 7.87$ & 0.218 & 0.196 & 0.093 \\
\hline $\begin{array}{l}\text { Frequency of abdomen waggles } \\
(\mathrm{Hz})\end{array}$ & $13.8 \pm 1.45$ & $13.6 \pm 1.08$ & 0.518 & 0.977 & 0.792 \\
\hline \multicolumn{6}{|l|}{ Return phase } \\
\hline Duration (ms) & $1635.9 \pm 686.63$ & $1248.7 \pm 367.68$ & 0.022 & 0.040 & 0.284 \\
\hline Number of wing-beating pulses $(n)$ & $4.9 \pm 3.49$ & $7.4 \pm 4.62$ & 0.099 & 0.922 & 0.603 \\
\hline $\begin{array}{l}\text { Combined duration of wing beating } \\
(\mathrm{ms})\end{array}$ & $76.6 \pm 61.31$ & $115.7 \pm 79.97$ & 0.168 & 0.790 & 0.324 \\
\hline $\begin{array}{l}\text { Duration of one wing-beating pulse } \\
(\mathrm{ms})\end{array}$ & $15.5 \pm 4.69$ & $14.5 \pm 3.94$ & 0.470 & 0.366 & 0.590 \\
\hline $\begin{array}{l}\text { Number of wing beats in one pulse } \\
\text { of wing beating }(n)\end{array}$ & $3.5 \pm 1.53$ & $3.4 \pm 1.04$ & 0.812 & 0.055 & 0.475 \\
\hline $\begin{array}{l}\text { Interval duration between } \\
\text { wing-beating pulses (ms) }\end{array}$ & $219.0 \pm 114.78$ & $154.5 \pm 132.25$ & 0.215 & 0.413 & 0.255 \\
\hline Frequency of wing beats $(\mathrm{Hz})$ & $222.6 \pm 39.27$ & $236.6 \pm 31.35$ & 0.263 & 0.001 & 0.574 \\
\hline $\begin{array}{l}\text { Frequency of wing-beating pulses } \\
\text { (Hz) }\end{array}$ & $3.1 \pm 1.97$ & $7.2 \pm 6.07$ & 0.016 & 0.438 & 0.675 \\
\hline
\end{tabular}

(Núñez 1982; Waddington 1982; Núñez and Giurfa 1996). Therefore, the hypothesis that the second group of dance components provides information about the food-source profitability might not be incorrect, because in the present study we investigated only one of many factors affecting food-source profitability. Consequently, some discrepancies between the results of the present study and the previous one (Łopuch and Tofilski 2017a) may result from the use of different methods. In the previous study, honey bee foragers were flying over much longer distances because the waggle phases consisted of up to 33 abdomen waggles, whereas in the present study the waggle phases consisted of 4 abdomen waggles, on average. Moreover, honey bees previously foraged spontaneously collecting nectar or pollen which they found themselves. As a result, the profitability of food sources in the 

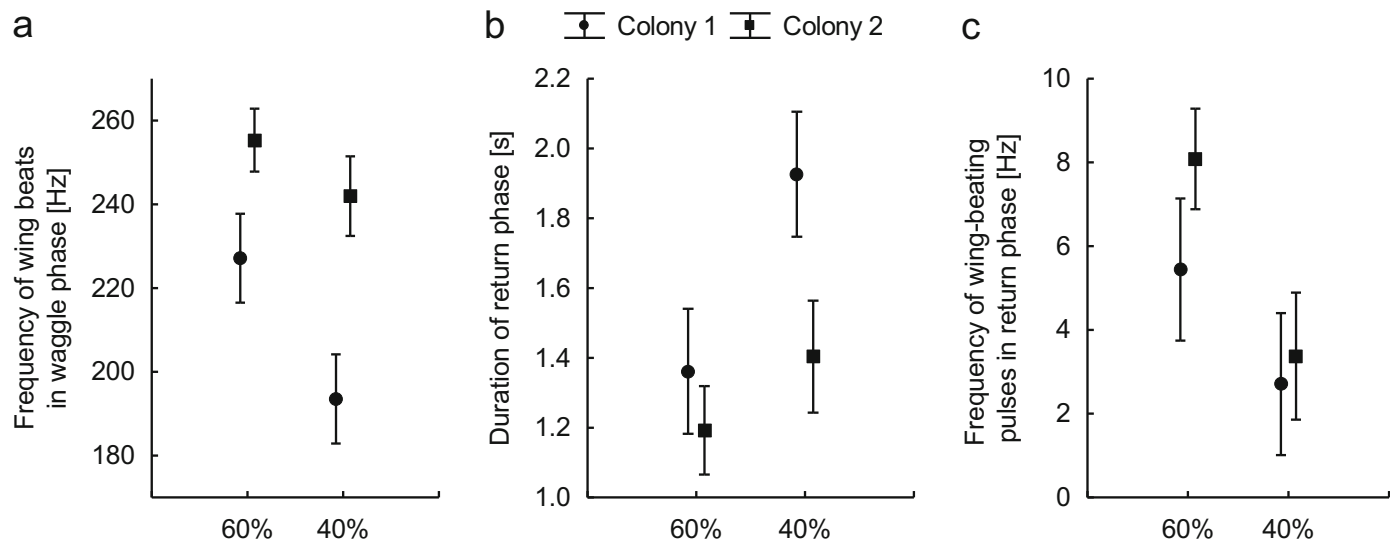

Honey concentration

Figure 2. The effect of 40 or $60 \%$ concentration of honey on dance components (mean $\pm \mathrm{SE}$ ): the frequency of wing beats in the waggle phase (a), the duration of return phase (b ), and the frequency of wing-beating pulses in the return phase (c).

previous experiment was most likely much more differentiated compared with the present experiment. This differentiation in food-source profitability resulting from differences in the food quality and the distance could be reflected much more strongly in the frequency of different dance components especially the frequency of wing beats and wing-beating pulses. It is likely that the present experiment was not sufficiently demanding for honey bee foragers to reveal more significant differences between both groups collecting honey solution at two different concentrations. Short distance might cause that both solutions were profitable for bees.

It should be mentioned that there were marked differences between colonies (Table II; Figure 2). This may reflect their different motivational state (Seeley 1986; Núñez and Giurfa 1996; De Marco and Farina 2001; Hrncir et al. 2011). The frequency of wing-beating pulses in the return phase seems to be the least influenced by the colony. On the other hand, the frequency of wing beats in the waggle phase was markedly different between

Table III. Standardized coefficients for canonical variables

\section{Variables}

Frequency of wing-beating pulses in return phase

Frequency of wing beats in waggle phase

Combined duration of wing beating in waggle phase

$-0.761$

Frequency of abdomen waggles in waggle phase

$-0.488$

Frequency of wing beats in return phase

$-0.407$

Number of wing beats in one pulse of wing beating in return phase

$-0.560$

Interval duration between wing-beating pulses in return phase

$-0.359$

Frequency of wing-beating pulses in waggle phase

Higher absolute values indicate a stronger influence of the variable on the discrimination between the food sources of different concentrations. A positive value indicates a higher value of the variable in the group with a higher concentration of honey in the food source 
colonies. The frequency corresponding to higher honey concentration in the first colony was lower than the frequency corresponding to lower honey concentration in the second colony (Figure 2c).

Honey bees are able to sense the low-frequency sounds and vibrations from 10 to $1000 \mathrm{~Hz}$ by Johnston's organ located in the antennae or the subgenual organ localised in the legs (Towne and Kirchner 1989; Kirchner et al. 1991; Dreller and Kirchner 1993; Kilpinen and Storm 1997). Therefore, it is likely that the followers detect the frequencies of wing beats, wing-beating pulses or abdomen waggles reported in the present study. The use of low-frequency sounds or vibrations in honey bee communication was reported including dance (Wenner et al. 1967; Waddington and Kirchner 1992), stop signal (Michelsen et al. 1986a; Schlegel et al. 2012), queen piping (Michelsen et al. 1986b), worker piping (Schlegel et al. 2012) and shaking signal (Gahl 1975). Most of those behaviours involve wing beating (Lopuch and Tofilski 2019). Different dance components are strongly correlated with each other allowing to transfer the same information in different ways, for instance the distance information is contained in the duration of waggle phase and the number of waggles (von Frisch and Jander 1957), which are significantly correlated with the combined duration of wing beating and the number of wing-beating pulses in the waggle phase (Łopuch and Tofilski $2017 b$ ) or the duration of sound production and the number of sound or vibratory pulses in the waggle phase (Wenner et al. 1967; Hrncir et al. 2011). The thoracic vibrations, and very likely wing beating, are produced by rapid contractions of wing muscles (Simpson 1964), and can be perceived by the followers as substrate vibrations (Tautz 1996), airborne sounds (Michelsen et al. 1986a, 1987) or tactile cues (Rohrseitz and Tautz 1999). Most likely that dance followers perceive various cues and integrate them to obtain more reliable information.

In conclusion, the results presented here indicate that information about the concentration of sugar in food sources is encoded mainly in the frequency of wing-beating pulses in the return phase, the frequency of wing beats in the waggle phase and the duration of return phase. However, other dance components, which are often strongly correlated with them, may also provide similar information. Both the waggle phase and the return phase seem to be important in transferring information about food-source quality.

\section{ACKNOWLEDGEMENTS}

We would like to thank the two anonymous reviewers for their suggestions and comments.

\section{AUTHOR CONTRIBUTION}

SŁ designed the experiment, performed the experiment and the analysis of video recordings; SŁ and AT analysed the results and wrote the manuscript; AT supervised the experiment.

\section{FUNDING INFORMATION}

This study was funded by the National Science Centre under grant DEC-2013/10/E/NZ9/00682.

\section{COMPLIANCE WITH ETHICAL STANDARDS}

Conflict of interest The authors declare that they have no conflict of interest.

\section{OPEN ACCESS}

This article is licensed under a Creative Commons Attribution 4.0 International License, which permits use, sharing, adaptation, distribution and reproduction in any medium or format, as long as you give appropriate credit to the original author(s) and the source, provide a link to the Creative Commons licence, and indicate if changes were made. The images or other third party material in this article are included in the article's Creative Commons licence, unless indicated otherwise in a credit line to the material. If material is not included in the article's Creative Commons licence and your intended use is not permitted by statutory regulation or exceeds the permitted use, you will need to obtain permission directly from the copyright holder. To view a copy of this licence, visit http://creativecommons. org/licenses/by/4.0/.

Impact de la qualité des sources alimentaires sur la fréquence du battement d'ailes des abeilles danseuses. 
abeille domestique / battements d'ailes / caméra à grande vitesse / qualité des aliments.

\section{Der Einfluss der Qualität der Futterquellen auf die Flügelschlagfrequenz von Tänzerinnen der Honigbiene.}

\section{Honigbiene / Flügelschlag / Hochfrequenzkamera / Qualität der Futterquellen.}

\section{REFERENCES}

Boch R. (1956) Die tänze der bienen bei nahen und fernen trachtquellen. Z. Vergl. Physiol. 38 (1-2), 136-167

De Marco R.J., Farina W.M. (2001) Changes in food source profitability affect the trophallactic and dance behavior of forager honeybees (Apis mellifera L.). Behav. Ecol. Sociobiol. 50 (5), 441-449

Dreller C., Kirchner W.H. (1993) Hearing in honeybees: localization of the auditory sense organ. J. Comp. Physiol. A 173, 275-279

Esch H. (1961) Über die schallerzeugung beim werbetanz der honigbiene. Z. Vergl. Physiol. 45 (1), 1-11

Esch H. (1963) Auswirkung der futterplatzqualität auf die schallerzeugung im werbanz der honigbiene. Verh. Dtsch. Zool. Ges. 26, 302-309

Esch H., Bastian J.A. (1970) How do newly recruited honey bees approach a food site? Z. Vergl. Physiol. $\mathbf{6 8}(2), 175-181$

Farina W.M. (1996) Food-exchange by foragers in the hive - a means of communication among honey bees? Behav. Ecol. Sociobiol. 38(1), 59-64

Gahl R.A. (1975) The shaking dance of honey bee workers: evidence for age discrimination. Anim. Behav. 23 (1), 230-232

Hrncir M., Maia-Silva C., Mc Cabe S.I., Farina W.M. (2011) The recruiter's excitement-features of thoracic vibrations during the honey bee's waggle dance related to food source profitability. J. Exp. Biol. 214 (23), 4055-4064

Judd T.M. (1995) The waggle dance of the honey bee: which bees following a dancer successfully acquire the information? J. Insect Behav. 8 (3), 343-354

Kilpinen O., Storm J. (1997) Biophysics of the subgenual organ of the honeybee, Apis mellifera . J. Comp. Physiol. A 181 (4), 30-318

Kirchner W.H., Dreller C., Towne W.F. (1991) Hearing in honeybees: operant conditioning and spontaneous reactions to airborne sound. J. Comp. Physiol. A 168, 85-89

Łopuch S., Tofilski A. (2017a) Importance of wing movements for information transfer during honey bee waggle dance. Ethology. 123 (12), 974-980

Łopuch S., Tofilski A. (2017b) Direct visual observation of wing movements during the honey bee waggle dance. J. Insect Behav. 30 (2), 199-210

Łopuch S., Tofilski A. (2019) Use of high-speed video recording to detect wing beating produced by honey bees. Insect. Soc. 66, 235-244

Michelsen A., Kirchner W.H., Lindauer M. (1986a) Sound and vibrational signals in the dance language of the honeybee, Apis mellifera . Behav. Ecol. Sociobiol. 18, 207-212

Michelsen A., Kirchner W.H., Andersen B.B., Lindauer M. (1986b) The tooting and quacking vibration signals of honeybee queens: a quantitative analysis. J. Comp. Physiol. A 158, 605-611

Michelsen A., Towne W.F., Kirchner W.H., Kryger P. (1987) The acoustic near field of a dancing honeybee. J. Comp. Physiol. A 161, 633-643

Núñez J.A. (1982) Honeybee foraging strategies at a food source in relation to its distance from the hive and the rate of sugar flow. J. Apicult. Res. 21 (3), 139-150

Núñez J.A., Giurfa M. (1996) Motivation and regulation of honey bee foraging. Bee World 77 (4), 182-196

Rohrseitz K., Tautz J. (1999) Honey bee dance communication: waggle run direction coded in antennal contacts? J. Comp. Physiol. A 184, 463-470

Schlegel T., Visscher P.K., Seeley T.D. (2012) Beeping and piping: characterization of two mechano-acoustic signals used by honey bees in swarming. Naturwissenschaften. 99 (12), 1067-1071

Seeley T.D. (1986) Social foraging by honey bees: how colonies allocate foragers among patches of flowers. Behav. Ecol. Sociobiol. 19 (5), 343-354

Seeley T.D. (1994) Honey bee foragers as sensory units of their colonies. Behav. Ecol. Sociobiol. 34 (1), 51-62

Seeley T.D., Towne W.F. (1992) Tactics of dance in honey bees: do foragers compare dances? Behav. Ecol. Sociobiol. 30 (1), 59-69

Seeley T.D., Camazine S., Sneyd J. (1991) Collective decision-making in honey bees: how colonies choose among nectar sources. Behav. Ecol. Sociobiol. 28 (4), 277-290

Seeley T.D., Mikheyev A.S., Pagano G.J. (2000) Dancing honey bees tune both duration and rate of waggle-run production in relation to nectar-source profitability. J. Comp. Physiol. A 186 (9), 813-819

Simpson J. (1964) The mechanism of honey-bee queen piping. Z. Vergl. Physiol. 48, 277-282 
Spangler H.G. (1991) Do honey bees encode distance information into the wing vibrations of the waggle dance. J. Insect Behav. 4 (1), 15-20

Statsoft Inc. (2013) Statistica (data analysis software system), version 12.0. http://www.statsoft.com. Accessed 04 August 2019

Tautz J. (1996) Honeybee waggle dance: recruitment success depends on the dance floor. J. Exp. Biol. 199 (6), 1375-1381

Thom C., Gilley D.C., Hooper J., Esch H.E. (2007) The scent of the waggle dance. PLoS Biol. 5 (9), e228

Towne W.F., Kirchner W.H. (1989) Hearing in honey bees: detection of air-particle oscillations. Science. 244 (4905), 686-688

Vision Research Inc. (2015) PCC software, version 2.6. http://www.visionresearch.net. Accessed 04 August 2019

von Frisch K. (1967) The dance language and orientation of bees. Harvard University Press, Cambridge von Frisch K., Jander R. (1957) Über die Schwänzeltanz der Bienen. Z. Vergl. Physiol. 40 (3), 239-263

Waddington K.D. (1982) Honey bee foraging profitability and round dance correlates. J. Comp. Physiol. A 148 (3), 279-301

Waddington K.D., Kirchner W.H. (1992) Acoustical and behavioral correlates of profitability of food sources in honey bee round dances. Ethology. 92 (1), 1-6

Waddington K.D., Nelson C.M., Page R.E. Jr. (1998) Effects of pollen quality and genotype on the dance of foraging honey bees. Anim. Behav. 56 (1), 35-39

Wenner A.M., Wells P.H., Rohlf F.J. (1967) An analysis of the waggle dance and recruitment in honey bees. Physiol. Zool. 40 (4), 317-344

Publisher's note Springer Nature remains neutral with regard to jurisdictional claims in published maps and institutional affiliations. 